\title{
Invariant Natural Killer T Cells as Key Players in Host Resistance against Paracoccidioides brasiliensis
}

\author{
Joes Nogueira-Neto $\left(\mathbb{D},{ }^{1}\right.$ Flavio V. Loures $\mathbb{D}^{2,3}$ Alessandra S. Schanoski ${ }^{2},^{2}$ \\ David A. G. Andrade $\mathbb{D}^{1},{ }^{1}$ Michelangelo B. Gonzatti $\mathbb{D}^{1},{ }^{1}$ Tania A. Costa, ${ }^{2}$ Bruno C. Vivanco ${ }^{D}{ }^{1}$ \\ Patrícia Xander $\mathbb{D}^{4},{ }^{4}$ Daniela S. Rosa ${ }^{\mathbb{D}},{ }^{1}$ Vera L. G. Calich $\mathbb{D}^{2},{ }^{2}$ and Alexandre C. Keller $\mathbb{D}^{1}$ \\ ${ }^{1}$ Departamento de Microbiologia, Imunologia e Parasitologia, Escola Paulista de Medicina, Universidade Federal de São Paulo, Brazil \\ ${ }^{2}$ Departamento de Imunologia, Instituto de Ciências Biomédicas, Universidade de São Paulo, Brazil \\ ${ }^{3}$ Instituto de Ciência e Tecnologia, Universidade Federal de São Paulo, Campus São José dos Campos, Brazil \\ ${ }^{4}$ Departamento de Ciências Farmacêuticas, Instituto de Ciências Ambientais, Químicas e Farmacêuticas, Universidade Federal de \\ São Paulo, Campus Diadema, Brazil
}

Correspondence should be addressed to Alexandre C. Keller; ackeller@unifesp.br

Received 23 December 2020; Revised 25 February 2021; Accepted 26 March 2021; Published 16 April 2021

Academic Editor: Luiz Felipe Domingues Passero

Copyright (C) 2021 Joes Nogueira-Neto et al. Th1is is an open access article distributed under the Creative Commons Attribution License, which permits unrestricted use, distribution, and reproduction in any medium, provided the original work is properly cited.

\begin{abstract}
Invariant Natural Killer T (iNKT) cells are key players in the immunity to several pathogens; however, their involvement in the resistance to Paracoccidioides brasiliensis infection remains unknown. Using splenocytes from CD1d $\left(\mathrm{CD} 1 \mathrm{~d}^{-/-}\right)$and $^{\mathrm{iNKT}-}$ deficient $\left(\mathrm{J} 18^{-/-}\right)$mice, we found that iNKT cells are the innate source of IFN- $\gamma$ after P. brasiliensis infection and are required to potentiate macrophage oxidative burst and control fungal growth. To determine whether iNKT cells contribute in vivo to host resistance against $P$. brasiliensis infection, we infected intratracheally wild-type and J $\alpha 18^{-1-}$ C57BL/6 mouse strains with the virulent $\mathrm{Pb} 18$ isolate. iNKT cell deficiency impaired the airway acute inflammatory response, resulting in decreased airway neutrophilia and reduced IFN- $\gamma, \mathrm{KC}$, and nitric oxide (NO) production. The deficient innate immune response of $\mathrm{J} \alpha 18^{-/-}$mice to $\mathrm{Pb} 18$ infection resulted in increased fungal burden in the lungs and spleen. Besides, the activation of iNKT cells in vivo by administration of the exogenous iNKT ligand $\alpha$-galactosylceramide $(\alpha$-GalCer) improved host resistance to $P$. brasiliensis infection. Although the mechanisms responsible for this phenomenon remain to be clarified, $\alpha$-GalCer treatment boosted the local inflammatory response and reduced pulmonary fungal burden. In conclusion, our study is the first evidence that iNKT cells are important for the protective immunity to P. brasiliensis infection and their activation by an exogenous ligand is sufficient to improve the host resistance to this fungal infection.
\end{abstract}

\section{Introduction}

Paracoccidioidomycosis (PCM) is caused by a fungus from the Paracoccidioides genus and is considered one of the highest causes of mortality among Brazilian systemic mycoses [1]. Clinical studies demonstrated a relationship between the characteristics of the immune response and disease severity [2]. In humans, a prominent Th1 response is associated with infection without disease, the chronic form of the disease with Th1/Th17 immunity, and the most severe manifestation, the acute or juvenile form, shows a prominent Th2/Th9 profile [1]. These data are supported by murine models of $P$. brasiliensis infection showing the association between the classical Th1 immune response, with high levels of IL-2 and IFN- $\gamma$, with resistance against the fungi $[3,4]$.

The lung is the primary site of fungal infection, where alveolar macrophages (MФ) recognize Pathogen-Associated Molecular Patterns (PAMPs) through several Pattern Recognition Receptors (PRRs) [5]. Although P. brasiliensis proliferates in resident alveolar $M \Phi$, these cells can inhibit fungal growth upon activation mediated by the synergistic action between lytic enzymes and metabolites from the oxidative 
burst that mediate fungal killing [6, 7]. In parallel, these cells potentiate the immunity against the fungi by secreting cytokines and chemokines that coordinate the influx and activation of other immune cells, such as neutrophils and $\mathrm{T}$ lymphocytes, to the site of infection [8]. In this scenario, Th1-biased lymphocytes increase the fungicidal ability of phagocytes, promoting resistance against the pathogen $[9,10]$. Although IFN- $\gamma$ drives the quality of the inflammatory response during the acute phase of $P$. brasiliensis infection, the source of the early IFN- $\gamma$ production remains unclear. Because invariant Natural Killer T (iNKT) lymphocytes are poised for the rapid production of IFN- $\gamma$, we hypothesized that they are important players in the immunity to $P$. brasiliensis infection [11].

The iNKT cells are a subpopulation of unconventional $\mathrm{T}$ lymphocytes that due to an invariant $\mathrm{T}$ cell receptor (TCR) promptly respond to lipid antigens presented in the context of CD1d molecules $[12,13]$. In addition to this unique specificity, they can rapidly secrete several cytokines and chemokines, acting as a bridge between innate and adaptive immunity $[14,15]$. This ability confers an essential immune regulatory function to these cells that participate in diverse types of immune responses, including those against pathogens $[16,17]$. Although a previous study described that iNKT cells from both healthy controls and cured PCM patients have the same ability to expand and produce cytokines, there are no data regarding their role in in vivo models of $P$. brasiliensis infection [18]. Therefore, we used the intratracheal model of $P$. brasiliensis infection with the virulent $\mathrm{Pb} 18$ strain, and wild-type (WT) and iNKT-deficient ( $\left.\alpha 18^{-/-}\right)$ C57BL-6 mice to determine the role of these cells in host resistance to $P$. brasiliensis $[13,19]$.

Our findings show that iNKT lymphocytes are the primary innate source of IFN- $\gamma$, and their deficiency leads to impaired airway inflammation and increased pulmonary fungal burden. Furthermore, the specific activation of iNKT cells by $\alpha$-galactosylceramide ( $\alpha$-GalCer) in an ongoing disease increased host resistance against this fungal pathogen. Therefore, iNKT cells were shown to play an essential role in shaping the protective immunity against the fungi, and the treatment with specific iNKT agonists potentiates host resistance to PCM.

\section{Materials and Methods}

2.1. Animals. Isogenic male $\mathrm{C} 57 \mathrm{Bl} / 6$ mice from wild-type (WT), CD1d ${ }^{-1-}$, and iNKT-deficient strain $\left(\mathrm{J} \alpha 18^{-/-}\right)$, aged 812 weeks, were obtained from the Animal Care Facility at the Federal University of São Paulo (UNIFESP). The C57Bl/ $6 \mathrm{~J} \alpha 18^{-/-}$strain was a gift from Dr. Masaru Taniguchi at the RIKEN Research Center for Allergy and Immunology (Japan) [13]. All animals were housed in individual standard cages and had free access to food and water. All procedures were previously reviewed and approved by the internal ethics committee of Universidade de São Paulo (USP-180/2011) and Universidade Federal de São Paulo (UNIFESP-CEP 0372/12).

2.2. Fungus. The virulent isolate $\mathrm{Pb} 18$ from Paracoccidioides brasiliensis was used throughout the experiments outlined in this work [20]. $\mathrm{Pb} 18$ yeast cells were subcultivated every seven days in semisolid Fava-Netto culture medium at $37^{\circ} \mathrm{C}$ until use. The yeast cells were collected and washed with sterile phosphate-buffered saline (PBS, pH 7.2). Fungal viability was determined by the Janus Green B vital dye. All experimental procedures were carried out with fungal suspensions presenting viability between 90 and $95 \%$.

2.3. Peritoneal $M \Phi$, Splenocytes, and In Vitro Culture. A sterile solution of $3 \%$ thioglycolate was injected in the peritoneal cavity, and four days later, peritoneal leukocytes were collected, and thioglycolate-elicited peritoneal $\mathrm{M} \Phi$ were isolated by adherence $\left(2 \mathrm{~h}\right.$ at $37^{\circ} \mathrm{C}$ in $\left.5 \% \mathrm{CO}_{2}\right)$ in plastic-bottom tissue-culture plates. Spleens were homogenized using the plunger end of a $3 \mathrm{~mL}$ syringe and a $70 \mu \mathrm{m}$ strainer, erythrocytes were removed using ACK solution $\left(0.15 \mathrm{M} \mathrm{NH}_{4} \mathrm{Cl}\right.$; $1 \mathrm{mM} \mathrm{KHCO}_{3} ; 0.1 \mathrm{mM} \mathrm{Na}_{2}$ EDTA), and cell viability was determined using trypan blue. After removing nonadherent cells, $M \Phi$ were cultivated alone or with $P$. brasiliensis yeasts in an $M \Phi$ : yeast ratio of $10: 1\left(2 \mathrm{~h}\right.$ at $37^{\circ} \mathrm{C}$ in $\left.5 \% \mathrm{CO}_{2}\right)$ to allow fungi adhesion and ingestion. Supernatants were removed, and cells were gently washed with PBS to remove any noningested or nonadherent yeast. After that, splenocytes from $\mathrm{WT}, \mathrm{CD} 1 \mathrm{~d}^{-/-}$or $\mathrm{J} \alpha 18^{-/-}$mice were added to the culture in an $\mathrm{M} \Phi$ : splenocyte ratio of $1: 10$. After $48 \mathrm{~h}$ of coculture, supernatants were collected and analyzed for IFN- $\gamma$, IL-10, and NO production. After removing coculture supernatants, the wells were washed with distilled water to lyse the cells, and suspensions were collected in individual tubes. Cell homogenates were assayed for the presence of viable yeasts, as previously described [21].

2.4. Colony-Forming Units Assay. The number of viable $\mathrm{Pb} 18$ yeasts in cell cultures and infected organs was determined by counting the number of colony-forming units (CFU) as previously described [21].

2.5. Induction of Experimental PCM. Animals were deeply anesthetized and infected by intratracheal (i.t.) delivery of 1 $\mathrm{x} 10^{6}$ viable $\mathrm{Pb}$ yeast cells. Animals were euthanized 72 hours postinfection to assess iNKT cells' role in the acute phase of infection. Depending on the objective of the experiment, euthanasia occurred forty-five days or eight weeks postinfection to determine the severity of $\mathrm{Pb}$ infection.

2.6. Bronchoalveolar Lavage Fluid (BAL). To determine the content of inflammatory cells in the airways, mice were euthanatized, the trachea was surgically exposed, and $0.5 \mathrm{~mL}$ of cold PBS was injected with a plastic cannula to obtain the BAL. After BAL collection, the total number of cells was determined in the Neubauer chamber and samples were centrifuged for supernatant analysis. Cellular precipitated was suspended in PBS for cytocentrifugation (Shandon, USA or Fanem, Br), and cellular populations were analyzed upon slides staining with hematoxylin/eosin.

2.7. Cytokine and Chemokine Production. IFN- $\gamma$ and KC levels in BAL were analyzed with a multiplex kit (Millipore, USA) following the manufacturer's recommendations. The 


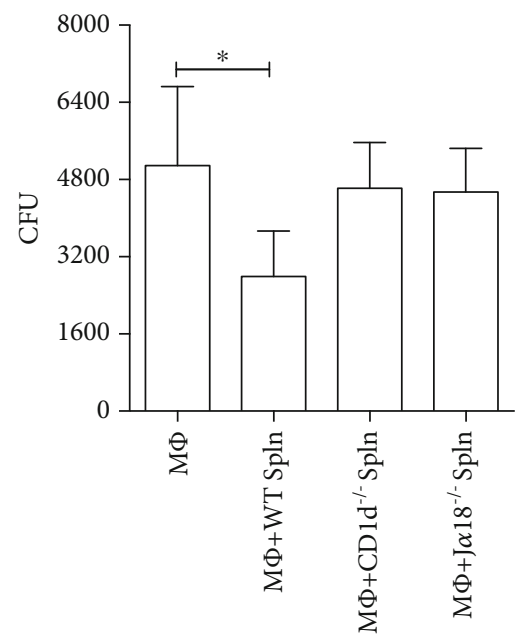

(a)

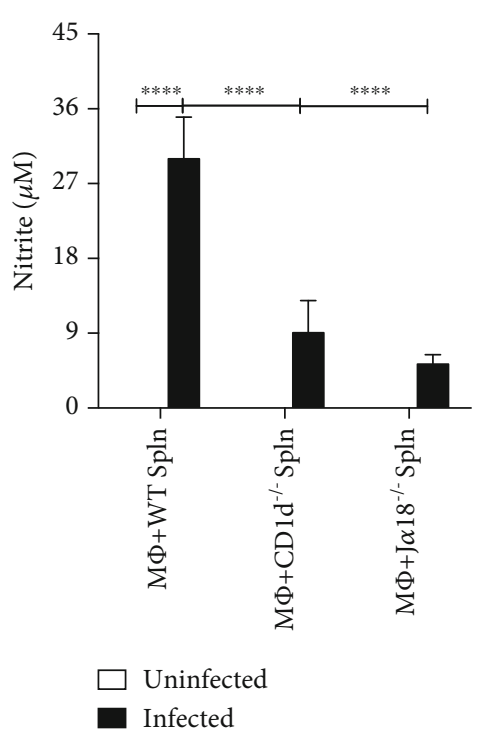

(b)

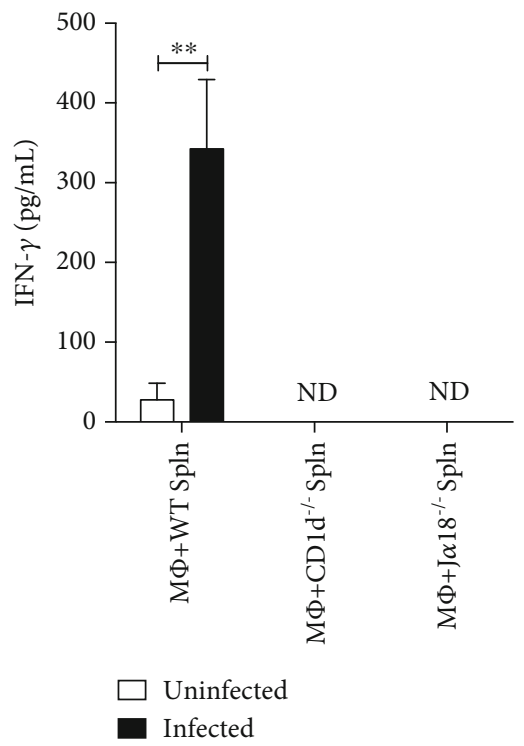

(c)

FIgURe 1: The invariant Natural Killer T cells drive P. brasiliensis killing by macrophages and respond for the innate source of IFN- $\gamma$ upon fungal infection. Thioglycolate-elicited peritoneal $\mathrm{M} \Phi$ from $\mathrm{C} 57 \mathrm{Bl} / 6$ mice were infected with Pb18 yeast $(1: 10)$ for $2 \mathrm{~h}$. After washing, splenocytes (Spln) from WT, CD1d ${ }^{-/-}$, or $\mathrm{J} \alpha 18^{-/-} \mathrm{C} 57 \mathrm{BL} / 6$ mouse strains were added to the M $\Phi$ culture (10:1) for $48 \mathrm{~h}$. After this period, supernatant was collected, and adherent cells were lysed with distilled water for fungal recovery. (a) Number of viable cell yeast obtained by colony-forming units assay (CFU). (b) NO levels in culture supernatants. (c) IFN- $\gamma$ levels in the culture supernatants (ND =not detected). Data represent the mean \pm SD of quintuplicate samples from 1 of 2 independent experiments (a, b) and of 1 independent experiment (c). ${ }^{*} p<0.05 ;{ }^{* *} p<0.005 ;{ }^{* * * *} p<0.0001$.

IFN- $\gamma$ levels in culture supernatants were quantified using ELISA (R\&D Systems, USA).

2.8. Nitric Oxide Production. Nitric oxide production in BAL was assessed using Nitrate/Nitrite Colorimetric Assay (Cayman Chemicals, USA) according to the manufacturer's recommendations. In culture supernatants, NO production was quantified by nitrite accumulation in the supernatants using a standard Griess reaction [22].

2.9. Flow Cytometry Assay. To determine the inflammatory state of lung parenchyma, the organs were digested with a DNAse $(1 \mathrm{mg} / \mathrm{mL}$ ) and collagenase $(2 \mathrm{mg} / \mathrm{mL}$ ) solution (Invitrogen), homogenized, centrifuged in Percoll 35\% (G\&E, USA) solution, and stained for different surface markers (eBioscience, USA). The T lymphocyte population was analyzed according to the expression of CD3, CD4, CD8, and CD69. Myeloid-derived cells were analyzed according to the expression of GR1, CD11b, and MHC-II. All data concerning the FACS assays were analyzed using the FlowJo software (BD, USA), according to specific cell population characteristics. Further information about analysis strategy is presented in Supplementary Figures 1 and 2.

2.10. $\alpha$-Galactosylceramide Treatment. At the week 4 after infection, mice were treated intravenously (i.v.) with $10 \mu \mathrm{g}$ of the NKT cell agonist $\alpha$-GalCer (KRN7000, Cayman Chemical Company, USA) and euthanized four weeks later to determine the fungal burden in the lung.
2.11. Statistical Analysis. For the comparison between two groups, we used a 2-tailed unpaired $t$-test, and for multiple comparisons, we used a two-way ANOVA followed by Turkey's or Bonferroni's multiple comparison test. All statistical analyses were performed using the GraphPad Prism 7 software (San Diego, CA).

\section{Results}

3.1. Invariant Natural Killer T Cells Are the Innate Source of IFN- $\gamma$ in Response to Fungal Infection and Are Required to Control P. brasiliensis Growth. To determine the role of the iNKT cells in the immunity against $P$. brasiliensis, we tested the ability of naïve splenocytes from $\mathrm{CD}_{1} \mathrm{~d}^{-/-}$mouse, deficient in diverse CD1d-restricted cells, or $\mathrm{J} \alpha 18^{-/-}$mouse strain, which lacks only the CD1d-restrict iNKT cell subset, to respond to fungal infection $[13,23]$. Thioglycolate-elicited peritoneal $\mathrm{M} \Phi$ were exposed to $\mathrm{Pb} 18$ yeasts for $2 \mathrm{~h}$, followed by coculture with $5 \times 10^{6}$ splenocytes from naive $\mathrm{WT}, \mathrm{CD} 1 \mathrm{~d}^{-/-}$, or $\mathrm{J} \alpha 18^{-/-}$ mice. Two days later, culture supernatants were collected, and $M \Phi$ were lysed to determine the number of viable yeasts. Figure 1(a) demonstrates that the addition of naive WT splenocytes to $M \Phi$ culture increased the fungicidal activity of macrophages. In contrast, splenocytes from both $\mathrm{CD}^{-1 /}$ and $J \alpha 18^{-1-}$ mice failed to increase $M \Phi$ killing capacity, indicating that the ability of naive splenocytes to control fungal growth depends on iNKT cells. In concordance, coculture with splenocytes from WT mice resulted in a higher NO production than those from $\mathrm{CD}_{1} \mathrm{~d}^{-/}$and $\mathrm{J} 18^{-/-}$(Figure 1(b)). 


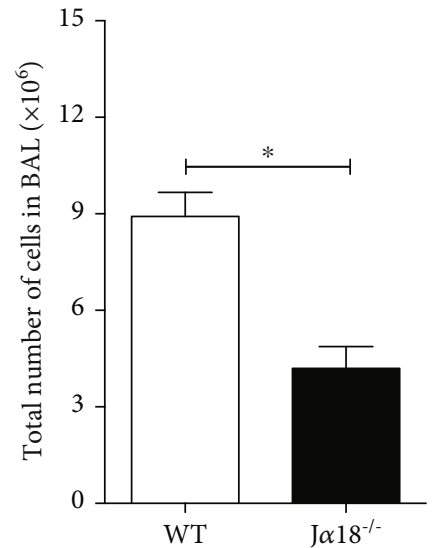

(a)

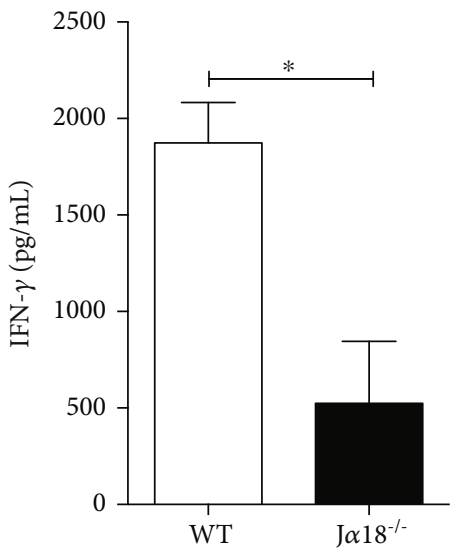

(c)

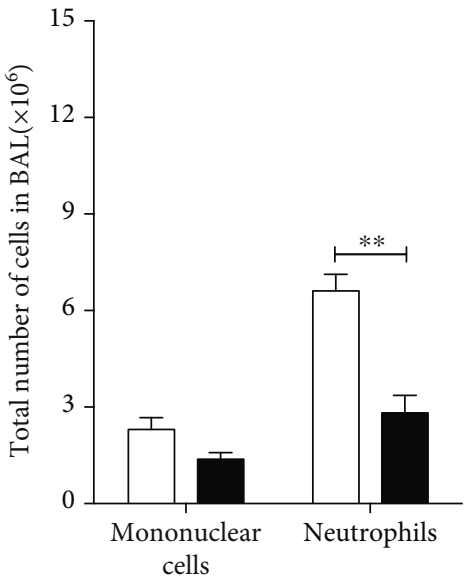

$\square \mathrm{WT}$

- $\mathrm{J} \alpha 18^{-1-}$

(b)

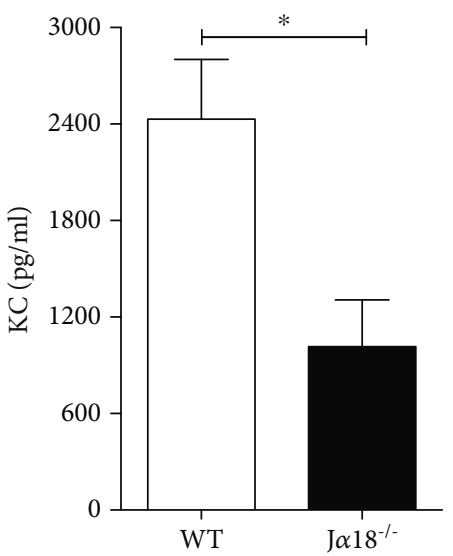

(d)

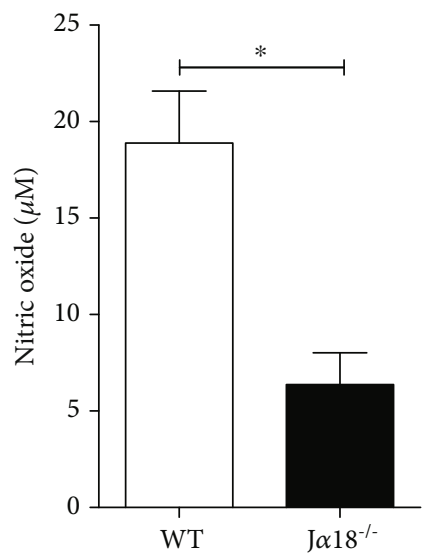

(e)

FIgure 2: Deficiency in invariant Natural Killer T lymphocytes impairs the acute inflammatory response against $P$. brasiliensis infection. WT and $\mathrm{J} \alpha 18^{-/-} \mathrm{C} 57 \mathrm{BL} / 6$ mouse strains were infected with $1 \times 10^{6} \mathrm{~Pb} 18$ yeasts, and $72 \mathrm{~h}$ later, the BAL content was analyzed for: (a) total number of cells; (b) presence of mononuclear cells and neutrophils; BAL levels of (c) IFN- $\gamma$, (d) KC, and (e) NO. Data represent the mean \pm SD from 1 of 2 independent experiments $\left(n=4-5\right.$ /group). ${ }^{*} p<0.05 ;{ }^{* *} p<0.005$.

Further analysis revealed that splenocytes from both $\mathrm{CD} 1 \mathrm{~d}^{-/-}$ and $\mathrm{J} \alpha 18^{-1-}$ failed to produce IFN- $\gamma$ in response to fungal infection (Figure 1(c)). Therefore, these data show that among
CD1d-restrict cells, the iNKT cell subset is the primary source of IFN- $\gamma$ during $P$. brasiliensis infection and essential for early control of fungal growth. 


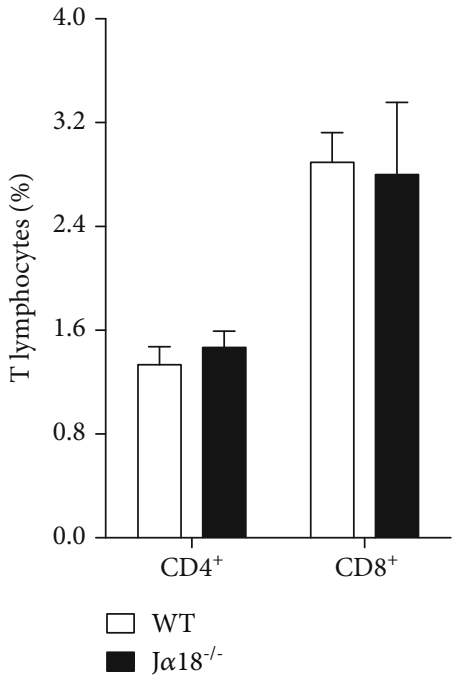

(a)

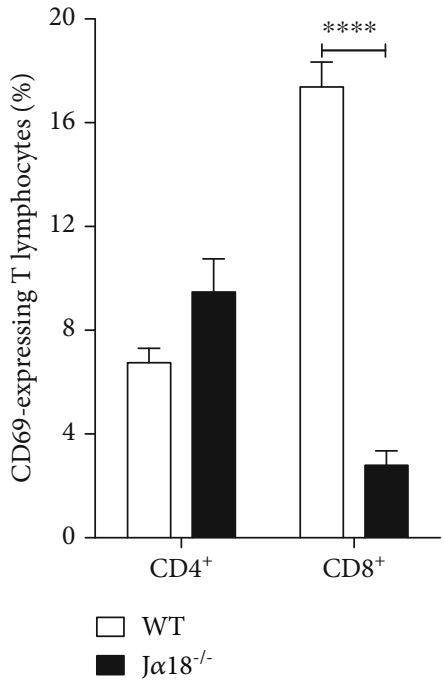

(b)

Figure 3: Deficiency in invariant Natural Killer T cells impairs early CD8 T lymphocyte activation during P. brasiliensis infection. WT and $\mathrm{J} \alpha 18^{-/-} \mathrm{C} 57 \mathrm{BL} / 6$ mouse strains were infected with $1 \times 10^{6} \mathrm{~Pb} 18$ yeasts, and $72 \mathrm{~h}$ later, the lung parenchyma was analyzed for: (a) frequency of $\mathrm{CD}^{+}$and $\mathrm{CD}^{+} \mathrm{T}$ lymphocytes and (b) frequency of CD69-expressing CD4 and CD8 T cells. Data represent the mean \pm SD from 1 of 2 independent experiments ( $n=5$ /group). ${ }^{* * * *} p<0.0001$.

3.2. Deficiency in iNKT Cells Impairs the Acute Airway Inflammation upon $P$. brasiliensis Infection. To determine the contribution of iNKT cells to the innate immune response against $P$. brasiliensis infection, we infected WT or $\mathrm{J} \alpha 18^{-/-} \mathrm{C} 57 \mathrm{Bl} / 6$ mice by intratracheal (i.t.) route with $1 \mathrm{x}$ $10^{6}$ living Pb18 yeast cells, and the BAL was collected $72 \mathrm{~h}$ later. $\mathrm{J} \alpha 18^{-/-}$mice presented a lower number of cells in the BAL compared to WT animals, which reflected an impaired airway neutrophilia (Figures 2(a) and 2(b), respectively). In accordance, the absence of iNKT cells resulted in lower levels of proinflammatory cytokines and chemokines, such as IFN$\gamma$ and $\mathrm{KC}$ in the airways (Figures 2(c) and 2(d), respectively). Moreover, NO levels in BAL were lower in the $\mathrm{J} \alpha 18^{-/-}$animals than in the WT group (Figure 2(e)). Therefore, these data demonstrate that iNKT cells play an important role in the acute phase of the inflammatory response following pulmonary $\mathrm{Pb} 18$ infection.

3.3. iNKT Cells Drive Early CD8 T Cell Activation and Influence the Presence of Distinct $G R 1^{+} C D 11 b^{+}$Cellular Population in the Lungs of Infected Mice. The flow cytometric analysis of lung parenchyma did not reveal any significant difference in the frequency of $\mathrm{CD}^{4}$ and $\mathrm{CD}^{8} \mathrm{~T}$ lymphocytes between WT and $\mathrm{J} \alpha 18^{-/-}$mice (Figure 3(a)). However, the frequency of $\mathrm{CD}^{+} \mathrm{CD}^{+} 9^{+} \mathrm{T}$ cells in the $\mathrm{J} \alpha 18^{-/-}$was lower than observed in WT group (Figure 3(b)). Because CD69 molecule represents an early activation marker, this result indicates that iNKT cells are required for the early activation of $\mathrm{CD}^{+} \mathrm{T}$ cells [24]. No significant difference was observed regarding CD69 expression in the $\mathrm{CD} 4^{+}$subset.

Further analysis revealed the presence of distinct $\mathrm{GR}^{+-}$ $\mathrm{CD}_{11 \mathrm{~b}^{+} \mathrm{SSC}}{ }^{\text {high }}$ and $\mathrm{GR} 1^{+} \mathrm{CD} 11 \mathrm{~b}^{+} \mathrm{SSC}^{\text {low }}$ cellular populations between WT and $\mathrm{J} \alpha 18^{-/-}$animals (Figure 4). We first found that the $\mathrm{GR} 1^{+} \mathrm{CD} 11 \mathrm{~b}^{+} \mathrm{SSC} \mathrm{h}^{\text {high }}$, but not the $\mathrm{GR} 1^{+-}$

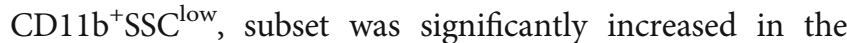
$\mathrm{J} \alpha 18^{-/-}$group versus WT animals (Figures $4(\mathrm{a})$ and $4(\mathrm{~d})$, respectively). These cellular populations have been described as suppressor or effector myeloid cells according to their functional state [25]. Therefore, to better characterize their immunological status, we first determined the surface expression of the MHC-II molecule [26]. In the WT group, the frequency of MHC-II-expressing cells and its surface expression was higher in both $\mathrm{GR} 1^{+} \mathrm{CD} 11 \mathrm{~b}^{+} \mathrm{SSC} \mathrm{C}^{\text {high }}$ and $\mathrm{GR} 1^{+-}$ $\mathrm{CD}_{1} 1 \mathrm{~b}^{+} \mathrm{SSC}^{\mathrm{low}}$ cells indicating a proinflammatory profile (Figures 4(b), 4(c), 4(e), and 4(f), respectively) [26]. This notion is corroborated by a higher surface expression of CD11b molecule, especially within the $\mathrm{GR} 1^{+} \mathrm{CD} 11 \mathrm{~b}^{+} \mathrm{SSC}^{\text {low }}$ subset (Figures 4(g) and 4(h)) [27].

3.4. Deficiency in iNKT Cells Impairs Host Resistance against $P$. brasiliensis Infection. Because iNKT deficiency impaired the early immune response against $\mathrm{Pb} 18$, we next determined their influence on a late phase of fungal infection. To this end, WT and $\mathrm{J} \alpha 18^{-/-}$mice were infected with $1 \times 10^{6}$ living $\mathrm{Pb}$ yeast cells, and 45 days later, the lungs, spleen, and liver were analyzed to determine fungal loads. Figures 5(a) and 5 (b) demonstrate that $\mathrm{J} \alpha 18^{-/-}$mice presented a higher number of viable fungal cells in the lungs and spleen than WT animals. No differences in CFUs were detected in the livers (Figure 5(c)). These data indicate that the absence of iNKT cells increases the susceptibility of iNKT-deficient mice to $\mathrm{Pb} 18$ infection and support the idea that iNKT cells are important to control fungal growth at the site of infection and its dissemination to other organ.

3.5. Treatment of Mice with an iNKT Cells Agonist ( $\alpha$-GalCer) Confers Resistance to $P$. brasiliensis Infection. It is well described that activation of iNKT cells by exogenous ligands, 


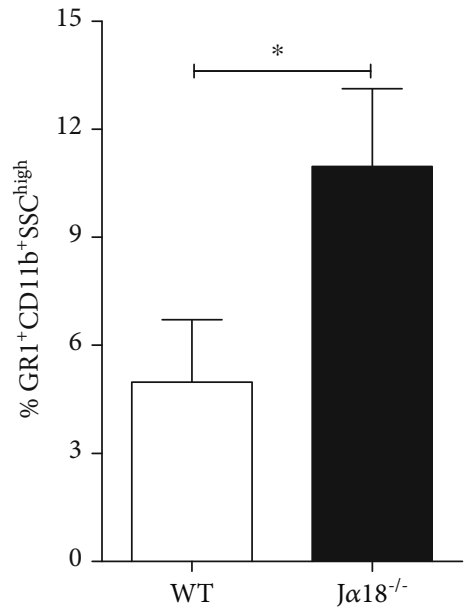

(a)

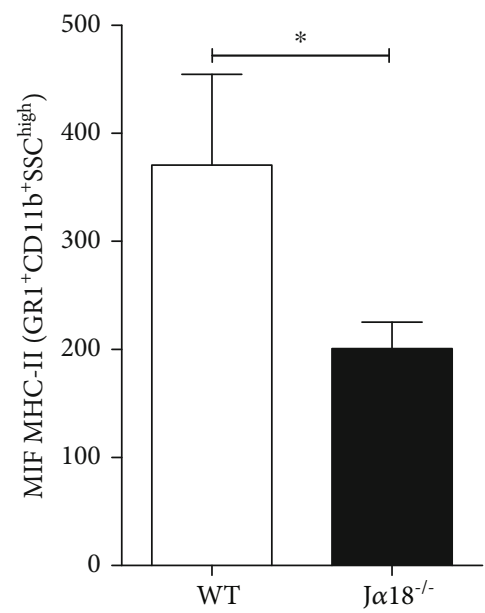

(c)

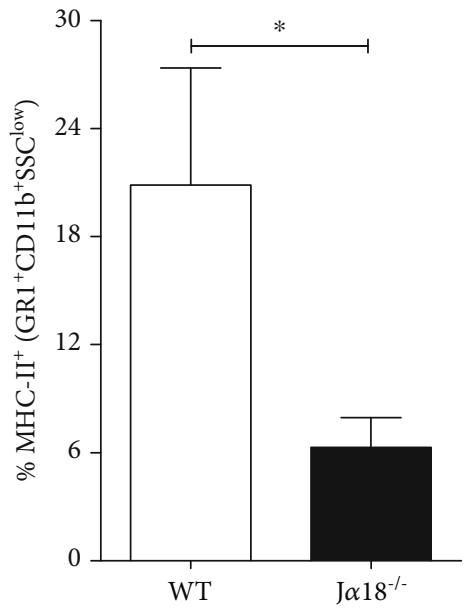

(e)

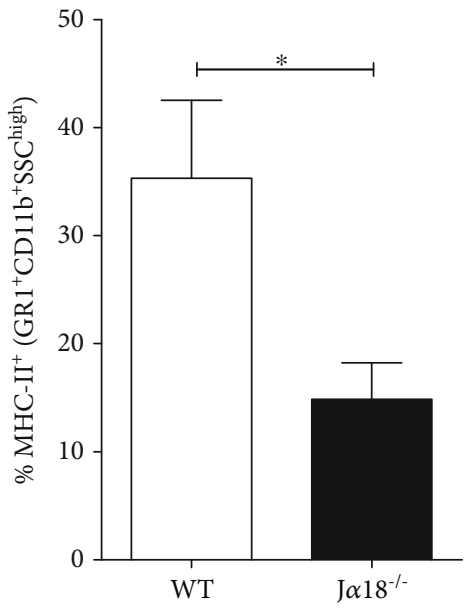

(b)

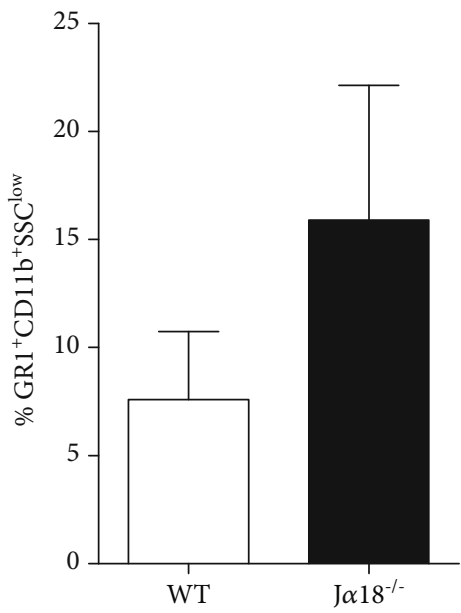

(d)

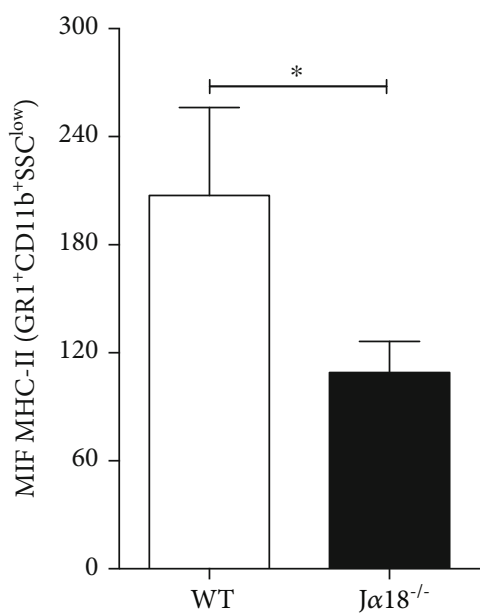

(f)

FIgUre 4: Continued. 


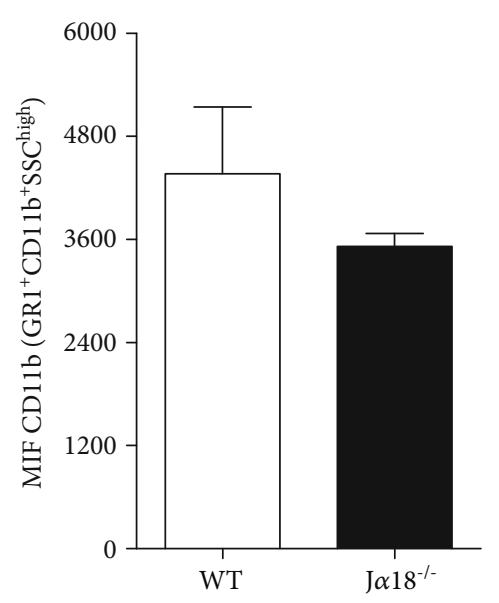

(g)

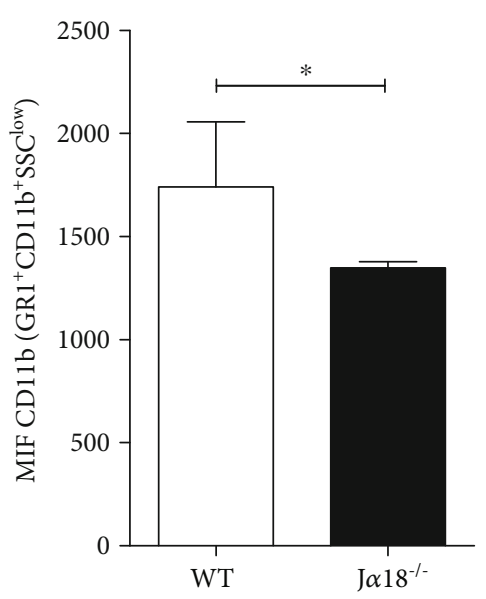

(h)

FIGURE 4: iNKT cells deficiency is associated with the accumulation of suppressor myeloid-derived cells in the lungs of $P$. brasiliensis infected mice. WT and $\mathrm{J} \alpha 18^{-/-} \mathrm{C} 57 \mathrm{BL} / 6$ mouse strains were infected with $1 \times 10^{6} \mathrm{~Pb} 18$ yeasts, and $72 \mathrm{~h}$ later, the lung parenchyma was analyzed for: Frequency of (a) GR1 $1^{+} \mathrm{CD} 11 \mathrm{~b}^{+} \mathrm{SCC} \mathrm{C}^{\text {high }}$ and (b) GR $1^{+} \mathrm{CD} 11 \mathrm{~b}^{+} \mathrm{SCC}{ }^{\text {low }}$ myeloid-derived cells. Frequency of MHC-II-expressing cells within (b) $\mathrm{GR} 1^{+} \mathrm{CD} 11 \mathrm{~b}^{+} \mathrm{SCC} \mathrm{C}^{\text {high }}$ and (e) GR $1^{+} \mathrm{CD} 11 \mathrm{~b}^{+} \mathrm{SCC}^{\text {low }}$ subsets and MHC-II surface expression level (c, f, respectively). Expression levels of $\mathrm{CD} 11 \mathrm{~b}$ molecules within the (g) $\mathrm{GR} 1^{+} \mathrm{CD} 11 \mathrm{~b}^{+} S C C^{\text {high }}$ and (h) $\mathrm{GR} 1^{+} \mathrm{CD} 11 \mathrm{~b}^{+} S C C^{\text {low }}$ myeloid-derived cells subsets. Data represent the mean \pm SD from 1 of 2 independent experiments ( $n=5$ /group). ${ }^{*} p<0.05$.

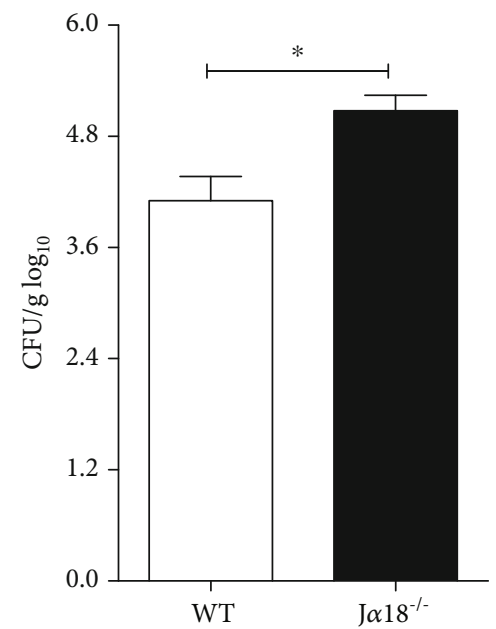

(a)

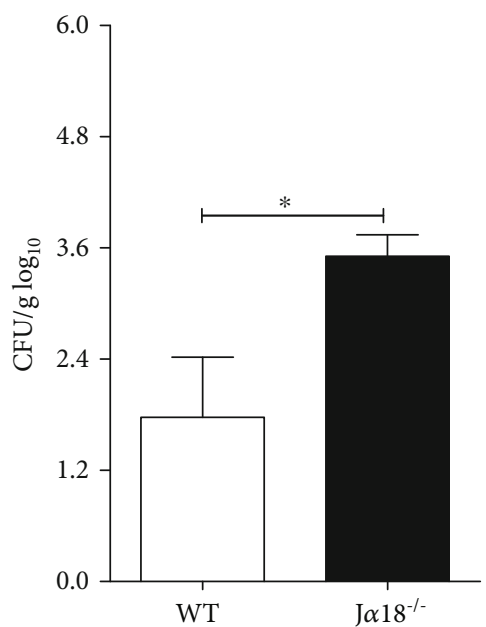

(b)

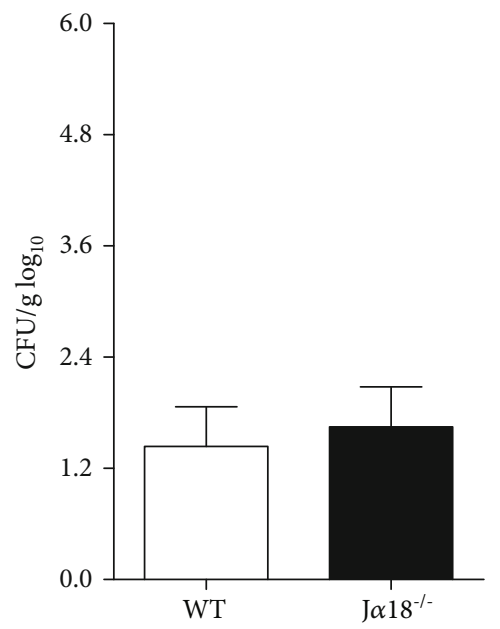

(c)

Figure 5: Invariant Natural Killer T cells restrain P. brasiliensis growth and dissemination. WT and J $\alpha 18^{-/-}$C57BL/6 mouse strains were infected with $1 \times 10^{6} \mathrm{~Pb} 18$ yeast, and 45 days later, the fungal loads were determined in the lungs (a), spleen (b), and liver (c). Data represent the mean $\pm \mathrm{SD}$ from 1 of 2 independent experiments $\left(n=5\right.$ /group). ${ }^{*} p<0.05$.

especially $\alpha$-GalCer, modulates different immune responses [28]. Thus, C57Bl/6 WT mice were treated with $10 \mu \mathrm{g}$ of $\alpha$ GalCer at week four after infection to test its effect on the host resistance to $P$. brasiliensis infection. Briefly, four weeks after i.t. infection with $1 \times 10^{6}$ living yeasts, infected mice received one single i.v. injection of $10 \mu \mathrm{g}$ of $\alpha$-GalCer, and four weeks later, the influx of leukocytes to the airways and pulmonary fungal loads was determined.

The $\alpha$-GalCer treatment resulted in a more intense inflammatory reaction against $P$. brasiliensis inoculation. The total number of cells and number of neutrophils were higher in the BAL of $\alpha$-GalCer-treated mice compared to nontreated mice (Figures 6(a) and 6(b), respectively). This increased inflammatory response was concomitant with lower fungal loads in the lungs of $\alpha$-GalCer-treated mice (Figure 6(c)). Therefore, these data further indicate the protective role of iNKT cells and suggest that iNKT activation by specific agonist can be used as a possible therapeutic tool in pulmonary paracoccidioidomycosis.

\section{Discussion}

Paracoccidioides brasiliensis is an opportunistic fungus, which causes occasional, self-limited, infections in the majority of immunocompetent individuals. However, systemic spreading with severe clinical manifestations has been 


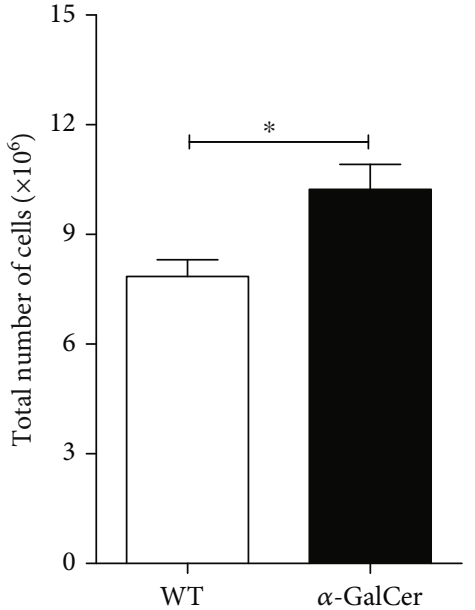

(a)

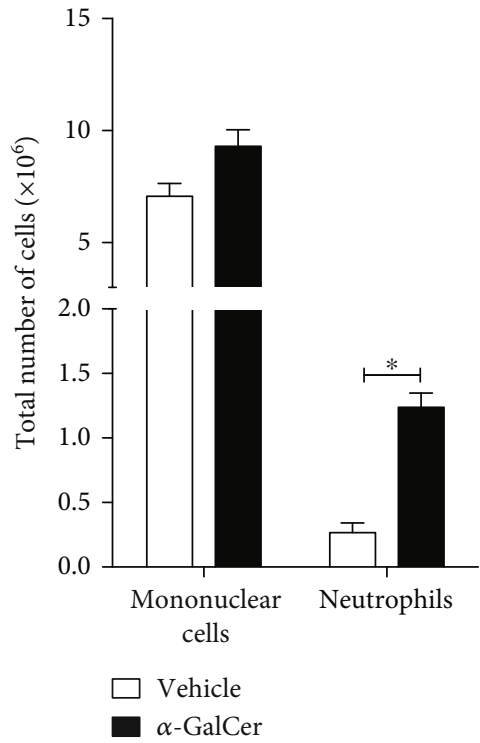

(b)

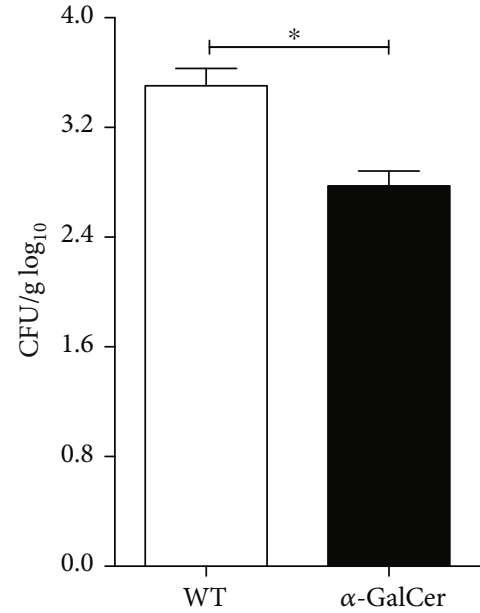

(c)

Figure 6: Treatment of $P$. brasiliensis infected mice with $\alpha$-GalCer, an iNKT specific agonist, enhances host resistance to $P$. brasiliensis infection. WT C57BL/6 mice were infected with $1 \times 10^{6} \mathrm{~Pb} 18$ yeasts and treated four weeks later with $10 \mu \mathrm{g}$ of $\alpha$-GalCer by the i.v. route. At week 8 after infection, the number of inflammatory cells in the BAL and the number of viable yeasts in the lung parenchyma of $\alpha$ GalCer-treated and untreated mice were determined. (a) Total number of inflammatory cells in BAL. (b) Mononuclear and neutrophil cell counts in the airways. (c) Fungal loads in lung parenchyma. Data represent the mean \pm SD from 1 independent experiment $(n=5 /$ group). ${ }^{*} p<0.05$.

correlated with intrinsic genetic characteristics of hosts, such as primary immunodeficiencies and individual lifestyle such as smoking, alcohol abuse, malnutrition, and treatment with immunosuppressive drugs $[29,30]$. Despite the extensive literature about the importance of innate immunity in the acute host response to infection and fungal control, the role of iNKT cells remains unknown [31]. To determine the impact of invariant Natural Killer T cells in P. brasiliensis infection, we used animals that lack the CD1d molecule, which are deficient in diverse CD1d-restricted cells, or the J $\alpha 281$ TCR gene segment $\left(\mathrm{J} \alpha 18^{-/-}\right)$, which results in the specific depletion of the iNKT phenotype $[13,23]$.

In response to the contact with $\mathrm{Pb}$-infected $\mathrm{M} \Phi$, naive splenocytes from WT mice produced high levels of IFN- $\gamma$, induced high levels of $\mathrm{NO}$, and controlled fungal growth. These findings corroborate the notion that in vitro control of fungal growth by macrophages correlates with the ability of splenocytes to produce IFN- $\gamma$ [32]. In contrast, splenic cells from CD1d ${ }^{-/-}$mice failed to produce IFN- $\gamma$, stimulate NO production, and control $P$. brasiliensis growth. Therefore, we could demonstrate that CD1d-restricted cells are responsible for the splenocytes IFN- $\gamma$ production in response to $P$. brasiliensis infection and exerted an essential role for the early contention of fungal growth.

Several studies demonstrated that CD1d-restricted T cells comprise distinct cell subpopulations [23]. Thus, to demonstrate that it was specifically the iNKT cell subset, the one that exerted a regulatory role in pulmonary PCM, we used the $\mathrm{J} \alpha 18^{-/-}$mice strain, which lacks these cells due to the deletion of the J $\alpha 281$ gene segment [13]. Similar to $\mathrm{CD}^{-1 /-}$ splenocytes, naive cells from $\mathrm{J} \alpha 18^{-/-}$mice failed to produce IFN- $\gamma$, induce NO production, and control fungal growth. Because no IFN- $\gamma$ production was detected in the presence of naive splenocytes from both $\mathrm{CD}_{1 \mathrm{~d}^{-/-}}$or $\mathrm{J} \alpha 18^{-/-}$mice, it is conceivable to assume that the iNKT cells are responsible for the IFN- $\gamma$ secretion and the control of fungal growth by $P$. brasiliensis infected $M \Phi$.

To determine the in vivo influence of iNKT cells on host response to $P$. brasiliensis, we took advantage of the murine model of intratracheal fungal infection. The BAL analysis revealed that during the early phase of infection, the absence of iNKT cells impaired the migration of inflammatory cells to the airways, as determined by reduced airway neutrophilia. In parallel to this finding, iNKT cell deficiency also impaired KC production, a chemokine extensively described as a homing factor for neutrophils [33]. Although the mechanisms that control KC and neutrophilic inflammation are complex, it has been described that during $P$. brasiliensis infection, IFN- $\gamma$ mediates diverse chemokines production, including $\mathrm{KC}$ [34]. Thus, it is pertinent to suppose that the lower levels of $\mathrm{KC}$ found in the $\mathrm{BAL}$ of $\mathrm{J} \alpha 18^{-/-}$-infected mice result from impaired IFN- $\gamma$ production in the absence of iNKT cells. Although iNKT cells are rapid IFN- $\gamma$ producing cells, neutrophils also seem to contribute for IFN- $\gamma$ production during $P$. brasiliensis infection [35]. Thus, the reduced IFN- $\gamma$ levels in $\mathrm{J} \alpha 18^{-/-}$mice during the acute responses may result from the absence of iNKT cells and the consequent impairment of neutrophil recruitment. The reduced ability to produce IFN- $\gamma$ also impacted the secretion of fungicide, or fungistatic metabolites, such as nitric oxide (NO) [36].

The lung parenchyma analysis confirmed the in vivo inability of $\mathrm{J} \alpha 18^{-/-}$mice to mount a protective inflammatory 
response. During the acute phase of the infection, iNKT deficiency was associated with a lower frequency of CD69expressing $\mathrm{CD}^{+}$, but not $\mathrm{CD} 4^{+}, \mathrm{T}$ cells indicating their suboptimal activation. Although further experiments are required to better explore the relationship between iNKT and $\mathrm{CD}^{+}$cells during the acute phase of $\mathrm{P}$. brasiliensis infection, the cross-talk between iNKT cells and $\mathrm{CD}^{+} \mathrm{T}$ lymphocytes is a phenomenon well recognized. The generation of short-lived effector cells in peripheral lymphoid organs depends on an initial short-lived interaction (0-6h) followed by a prolonged-lasting contact (12-24h) [37]. Also, IFN- $\gamma$ production by iNKT cells is essential for the physiological induction of specific CD8 effector T cells [38]. Because the control of fungal loads has been associated with the $\mathrm{CD} 8^{+}$ T lymphocyte subset, it is possible to propose that iNKT cells play an important role in generating effector $\mathrm{CD}^{2} \mathrm{~T}^{+}$cells during the beginning of $P$. brasiliensis infection $[39,40]$. Furthermore, iNKT cell deficiency was also associated with the accumulation of myeloid-derived suppressor- (MDSC-) like cells. Although the interaction between iNKT lymphocytes and MDSC during infection remains unclear, there is evidence that activated iNKT cells can inhibit the immunosuppressive activity of MDSC [41, 42]. Myeloid cells expressing concomitantly the GR-1 and the CD11b markers represent a group of diverse polymorphonuclear (SSC ${ }^{\text {high }}$ ) and monocytic $\left(S_{S C}{ }^{\text {low }}\right)$ suppressor or effector cells $[25,26,43]$. Although a clear distinction between the suppressor or effector subsets requires very specific assays, the high expression of MHC-II and CD11b molecules may be used to distinguish between these cellular subsets $[26,27]$. In this context, we found that during $P$. brasiliensis infection, the frequency of GR- $1^{+} \mathrm{CD} 11 \mathrm{~b}^{+}$cells expressing low MHC-II and CD11b levels increased in the $\mathrm{J} \alpha 18^{-/-}$animals, suggesting the appearance of the suppressive subset. Thus, it is reasonable to hypothesize that the early activation of iNKT cells in response to $P$. brasiliensis modulates the appearance of MDSC in the pulmonary environment.

The results discussed above support the idea that the absence of iNKT lymphocytes leads to an immunocompromised microenvironment that impairs host resistance against $P$. brasiliensis infection. Indeed, the importance of iNKT cells in the immunity against $P$. brasiliensis is evident when comparing fungal burdens between WT and $\mathrm{J} \alpha 18^{-/-}$mice. iNKT cell deficiency resulted in higher fungal loads in both lungs and spleen compared to the WT mice, indicating that these cells are key players in the control of fungus dissemination.

Finally, a previous study demonstrated that a single high dose of $\alpha$-GalCer improved the outcome of Mycobacterium tuberculosis infection [44]. Thus, we next addressed the impact of $\alpha$-GalCer administration on P. brasiliensis-infected mice. Animals treated with $\alpha$-GalCer four weeks after fungal infection exhibited a significant reduction in the pulmonary fungal loads at week 8 after infection. Although the mechanisms involved in this phenomenon remain an object of study, fungal growth control was parallel to a more robust airway inflammatory response.

In conclusion, this study provides the first evidence of the contribution of iNKT cells to host resistance against $P$. brasiliensis infection and that their activation by exogenous ago- nists could be considered a therapeutic tool to improve immunity to infection.

\section{Data Availability}

Data is available under reasonable request.

\section{Conflicts of Interest}

Although ACK is a member of the academic editorial board from the Journal of Immunology Research, he declares no conflict of interest. All the other authors declare that there is no conflict of interest.

\section{Acknowledgments}

This study was supported by research grants from Fundação de Amparo à Pesquisa do Estado de São Paulo (ACK: 2012/04692-1 and 2016/02189-1; VLGC: 2011/51258-2; and 2016/23189-0), and Coordenação de Aperfeiçoamento de Pessoal de Nível Superior-Brasil (CAPES)-Finance code 001. ACK, DSR, FVL and VLGC have personal scientific grants from Conselho Nacional de Pesquisa e Desenvolvimento (CNPq).

\section{Supplementary Materials}

Supplemental Figure 1: analysis of CD4 and CD8 T lymphocytes in lung parenchyma. After exclusion of dead cells, the $\mathrm{CD}^{+}$cells were analyzed for $\mathrm{CD} 4$ or CD8 expression and the frequency of CD69-expressing cells was determined within these populations. Supplemental Figure 2: analysis of GR $-1^{+} \mathrm{CD} 11 \mathrm{~b}^{+}$subsets in lung parenchyma. After exclusion of dead cells, the GR-1 ${ }^{+}$cells, within the $\mathrm{CD} 11 \mathrm{~b}^{+}$subset, were analyzed according to SSC size (high or low). Next, both subsets were analyzed for MHC-II and CD11b expression. (Supplementary Materials)

\section{References}

[1] M. A. Shikanai-Yasuda, R. P. Mendes, A. L. Colombo et al., "Brazilian guidelines for the clinical management of paracoccidioidomycosis," Revista da Sociedade Brasileira de Medicina Tropical, vol. 50, no. 5, pp. 715-740, 2017.

[2] G. Benard, C. C. Romano, C. R. Cacere, M. Juvenale, M. J. Mendes-Giannini, and A. J. Duarte, "Imbalance of IL-2, IFN$\gamma$ and IL-10 secretion in the immunosuppression associated with human paracoccidioidomycosis," Cytokine, vol. 13, no. 4, pp. 248-252, 2001.

[3] S. S. Kashino, R. A. Fazioli, C. Cafalli-Favati et al., "Resistance to Paracoccidioides brasiliensis infection is linked to a preferential Th1 immune response, whereas susceptibility is associated with absence of IFN-gamma production," Journal of Interferon \& Cytokine Research, vol. 20, no. 1, pp. 89-97, 2000.

[4] S. R. Almeida and J. D. Lopes, "The low efficiency of dendritic cells and macrophages from mice susceptible to Paracoccidioides brasiliensis in inducing a Th1 response," Brazilian Journal of Medical and Biological Research, vol. 34, no. 4, pp. 529-537, 2001.

[5] V. L. Calich, A. Pina, M. Felonato, S. Bernardino, T. A. Costa, and F. V. Loures, "Toll-like receptors and fungal infections: the 
role of TLR2, TLR4 and MyD88 in paracoccidioidomycosis," FEMS immunology and Medical Microbiology, vol. 53, no. 1, pp. 1-7, 2008.

[6] A. P. Moreira, L. A. Dias-Melicio, M. T. Peracoli, S. A. Calvi, and A. M. Victoriano de Campos Soares, "Killing of Paracoccidioides brasiliensis yeast cells by IFN- $\gamma$ and TNF- $\alpha$ activated murine peritoneal macrophages: evidence of $\mathrm{H}_{2} \mathrm{O}_{2}$ and $\mathrm{NO}$ effector mechanisms," Mycopathologia, vol. 166, no. 1, pp. 17-23, 2008.

[7] D. Lopera, B. H. Aristizabal, A. Restrepo, L. E. Cano, and A. Gonzalez, "Lysozyme plays a dual role against the dimorphic fungus Paracoccidioides brasiliensis," Revista do Instituto de Medicina Tropical de Sao Paulo, vol. 50, no. 3, pp. 169-175, 2008.

[8] V. L. Calich, T. A. da Costa, M. Felonato et al., "Innate immunity to Paracoccidioides brasiliensis infection," Mycopathologia, vol. 165, no. 4-5, pp. 223-236, 2008.

[9] E. Brummer, L. H. Hanson, and D. A. Stevens, "Gamma-interferon activation of macrophages for killing of Paracoccidioides brasiliensis and evidence for nonoxidative mechanisms," International Journal of Immunopharmacology, vol. 10, no. 8, pp. 945-952, 1988.

[10] N. Kurita, S. K. Biswas, M. Oarada, A. Sano, K. Nishimura, and M. Miyaji, "Fungistatic and fungicidal activities of murine polymorphonuclear leucocytes against yeast cells of Paracoccidioides brasiliensis," Medical Mycology, vol. 37, no. 1, pp. 1924, 1999 .

[11] D. B. Stetson, M. Mohrs, R. L. Reinhardt et al., "Constitutive cytokine mRNAs mark natural killer (NK) and NK T cells poised for rapid effector function," Journal of Experimental Medicine, vol. 198, no. 7, pp. 1069-1076, 2003.

[12] T. Kawano, J. Cui, Y. Koezuka et al., "CD1d-restricted and TCR-mediated activation of valpha14 NKT cells by glycosylceramides," Science, vol. 278, no. 5343, pp. 1626-1629, 1997.

[13] J. Cui, T. Shin, T. Kawano et al., "Requirement for Valpha14 NKT cells in IL-12-mediated rejection of tumors," Science, vol. 278, no. 5343, pp. 1623-1626, 1997.

[14] J. L. Matsuda, T. Mallevaey, J. Scott-Browne, and L. Gapin, "CD1d-restricted iNKT cells, the 'Swiss-Army knife' of the immune system," Current Opinion in Immunology, vol. 20, no. 3, pp. 358-368, 2008.

[15] J. Klibi, L. Amable, and K. Benlagha, "A focus on NKT cell subset characterization and developmental stages," Immunology and Cell Biology, vol. 98, no. 7, p. 607, 2020.

[16] S. J. McKee, S. R. Mattarollo, and G. R. Leggatt, "Immunosuppressive roles of natural killer T (NKT) cells in the skin," Journal of Leukocyte Biology, vol. 96, no. 1, pp. 49-54, 2014.

[17] P. Arora, E. L. Foster, and S. A. Porcelli, "CD1d and natural killer T cells in immunity to Mycobacterium tuberculosis," Advances in Experimental Medicine and Biology, vol. 783, pp. 199-223, 2013.

[18] V. G. Batista, L. Moreira-Teixeira, M. C. Leite-de-Moraes, and G. Benard, "Analysis of invariant natural killer T cells in human paracoccidioidomycosis," Mycopathologia, vol. 172, no. 5, pp. 357-363, 2011.

[19] J. Defaveri, M. T. Rezkallah-Iwasso, and M. F. de Franco, "Experimental pulmonary paracoccidioidomycosis in mice: morphology and correlation of lesions with humoral and cellular immune response," Mycopathologia, vol. 77, no. 1, pp. 3-11, 1982.

[20] S. S. Kashino, V. L. Calich, E. Burger, and L. M. Singer-Vermes, "In vivo and in vitro characteristics of six Paracoccidioides brasiliensis strains," Mycopathologia, vol. 92, no. 3, pp. 173$178,1985$.

[21] L. M. Singer-Vermes, M. C. Ciavaglia, S. S. Kashino, E. Burger, and V. L. Calich, "The source of the growth-promoting factor(s) affects the plating efficiency of Paracoccidioides brasiliensis," Journal of Medical and Veterinary Mycology, vol. 30, no. 3, pp. 261-264, 1992.

[22] A. H. Ding, C. F. Nathan, and D. J. Stuehr, "Release of reactive nitrogen intermediates and reactive oxygen intermediates from mouse peritoneal macrophages. Comparison of activating cytokines and evidence for independent production," Journal of Immunology, vol. 141, no. 7, pp. 2407-2412, 1988.

[23] D. G. Pellicci and A. P. Uldrich, "Unappreciated diversity within the pool of CD1d-restricted T cells," Seminars in Cell \& Developmental Biology, vol. 84, pp. 42-47, 2018.

[24] R. Testi, J. H. Phillips, and L. L. Lanier, "Leu 23 induction as an early marker of functional CD3/T cell antigen receptor triggering. Requirement for receptor cross-linking, prolonged elevation of intracellular $[\mathrm{Ca}++]$ and stimulation of protein kinase C," Journal of Immunology, vol. 142, no. 6, pp. 1854-1860, 1989.

[25] A. Obregon-Henao, M. Henao-Tamayo, I. M. Orme, and D. J. Ordway, "Gr1(int)CD11b+ myeloid-derived suppressor cells in Mycobacterium tuberculosis infection," PLoS One, vol. 8, no. 11, article e80669, 2013.

[26] V. P. Makarenkova, V. Bansal, B. M. Matta, L. A. Perez, and J. B. Ochoa, "CD11b+/Gr-1+ myeloid suppressor cells cause T cell dysfunction after traumatic stress," Journal of Immunology, vol. 176, no. 4, pp. 2085-2094, 2006.

[27] M. Duan, D. P. Steinfort, D. Smallwood et al., "CD11b immunophenotyping identifies inflammatory profiles in the mouse and human lungs," Mucosal Immunology, vol. 9, no. 2, pp. 550-563, 2016.

[28] A. Schiefner, M. Fujio, D. Wu, C. H. Wong, and I. A. Wilson, "Structural evaluation of potent NKT cell agonists: implications for design of novel stimulatory ligands," Journal of Molecular Biology, vol. 394, no. 1, pp. 71-82, 2009.

[29] R. Martinez, "New trends in paracoccidioidomycosis epidemiology," Journal of Fungi, vol. 3, no. 1, p. 1, 2017.

[30] A. Restrepo, G. Benard, C. C. de Castro, C. A. Agudelo, and A. M. Tobon, "Pulmonary paracoccidioidomycosis," Seminars in Respiratory and Critical Care Medicine, vol. 29, no. 2, pp. 182-197, 2008.

[31] F. Cezar-Dos-Santos, J. P. Assolini, N. C. M. Okuyama, K. F. Viana, K. B. de Oliveira, and E. N. Itano, "Unraveling the susceptibility of paracoccidioidomycosis: insights towards the pathogen-immune interplay and immunogenetics," Infection, Genetics and Evolution, vol. 86, p. 104586, 2020.

[32] E. Brummer, L. H. Hanson, A. Restrepo, and D. A. Stevens, "In vivo and in vitro activation of pulmonary macrophages by IFN-gamma for enhanced killing of Paracoccidioides brasiliensis or Blastomyces dermatitidis," Journal of Immunology, vol. 140, no. 8, pp. 2786-2789, 1988.

[33] Y. Kobayashi, "Neutrophil infiltration and chemokines," Critical Reviews in Immunology, vol. 26, no. 4, pp. 307-316, 2006.

[34] J. T. Souto, J. C. Aliberti, A. P. Campanelli et al., "Chemokine production and leukocyte recruitment to the lungs of Paracoccidioides brasiliensis-infected mice is modulated by interferon- $\gamma$," The American Journal of Pathology, vol. 163, no. 2, pp. 583-590, 2003.

[35] P. A. Pino-Tamayo, J. D. Puerta-Arias, D. Lopera, M. E. UranJimenez, and A. Gonzalez, "Depletion of neutrophils 
exacerbates the early inflammatory immune response in lungs of mice infected with Paracoccidioides brasiliensis," Mediators of Inflammation, vol. 2016, Article ID 3183285, 17 pages, 2016.

[36] A. Gonzalez, W. de Gregori, D. Velez, A. Restrepo, and L. E. Cano, "Nitric oxide participation in the fungicidal mechanism of gamma interferon-activated murine macrophages against Paracoccidioides brasiliensis conidia," Infection and Immunity, vol. 68, no. 5, pp. 2546-2552, 2000.

[37] M. Valente, Y. Dolen, E. van Dinther et al., "Cross-talk between iNKT cells and CD8 $\mathrm{T}$ cells in the spleen requires the IL-4/CCL17 axis for the generation of short-lived effector cells," Proceedings of the National Academy of Sciences of the united States of America, vol. 116, no. 51, pp. 25816-25827, 2019.

[38] S. R. Mattarollo, M. Yong, L. Tan, I. H. Frazer, and G. R. Leggatt, "Secretion of IFN-gamma but not IL-17 by CD1drestricted NKT cells enhances rejection of skin grafts expressing epithelial cell-derived antigen," The Journal of Immunology, vol. 184, no. 10, pp. 5663-5669, 2010.

[39] A. P. Chiarella, C. Arruda, A. Pina, T. A. Costa, R. C. Ferreira, and V. L. Calich, "The relative importance of $\mathrm{CD}^{+}$and $\mathrm{CD}^{+} \mathrm{T}$ cells in immunity to pulmonary paracoccidioidomycosis," Microbes and Infection, vol. 9, no. 9, pp. 1078-1088, 2007.

[40] C. Paget, S. Ivanov, J. Fontaine et al., "Potential role of invariant NKT cells in the control of pulmonary inflammation and $\mathrm{CD} 8+\mathrm{T}$ cell response during acute influenza A virus $\mathrm{H} 3 \mathrm{~N} 2$ pneumonia," Journal of Immunology, vol. 186, no. 10, pp. 5590-5602, 2011.

[41] H. J. Ko, J. M. Lee, Y. J. Kim, Y. S. Kim, K. A. Lee, and C. Y. Kang, "Immunosuppressive myeloid-derived suppressor cells can be converted into immunogenic APCs with the help of activated NKT cells: an alternative cell-based antitumor vaccine," Journal of Immunology, vol. 182, no. 4, pp. 1818-1828, 2009.

[42] D. Wu, Y. Shi, C. Wang et al., "Activated NKT cells facilitated functional switch of myeloid-derived suppressor cells at inflammation sites in fulminant hepatitis mice," Immunobiology, vol. 222, no. 2, pp. 440-449, 2017.

[43] V. Damuzzo, L. Pinton, G. Desantis et al., "Complexity and challenges in defining myeloid-derived suppressor cells," Cytometry Part B: Clinical Cytometry, vol. 88, no. 2, pp. 7791, 2015.

[44] I. Sada-Ovalle, M. Skold, T. Tian, G. S. Besra, and S. M. Behar, "Alpha-galactosylceramide as a therapeutic agent for pulmonary Mycobacterium tuberculosis infection," American Journal of Respiratory and Critical Care Medicine, vol. 182, no. 6, pp. 841-847, 2010. 